\title{
Microwave Synthesis: A Physical Concept
}

\author{
V.K. Saxena and Usha Chandra \\ University of Rajasthan, Jaipur \\ India
}

\section{Introduction}

The term 'microwaves' is used for those wavelengths measured in centimetres roughly from $1 \mathrm{~m}$. to $0.1 \mathrm{~cm}$ or the bands of frequencies between $300 \mathrm{MHz}$ to $300 \mathrm{GHz}$. Microwaves are most popularly used in point to point communication, TV broadcasting via satellites and in RADAR systems. Besides these, they are also being used in industrial, biomedical, chemical and in scientific research applications. The latest wide acceptance of the microwave application is as "microwave heating" in synthesizing various compounds (organic and inorganic) in research laboratories as well as in industries. The serendipity experiment of radar-orientated research by Dr Percy Spencer in 1946 discovered the heating property of microwave (the candy bar melted in the pocket). Since then microwave radiation has opened up a new technology. The application is no longer confined to food industry, but shown impacts in other areas also. Inorganic synthesis, polymer curing, textile drying are growing industrial areas where microwaves are being used. The first published reports on the use of microwave irradiation to carry out organic chemical transformation by the group of Gedye (1986) and Giguere et al.(1986), it has emerged as an promising technology in medicinal chemistry, polymer synthesis, material sciences, nanotechnology and biochemical processes. In the early days of microwave synthesis, experiments were carried out in sealed Teflon or glass vessels in a domestic oven without any pressure or temperature measurements, sometimes resulting into violent explosion due to rapid uncontrolled heating in organic solvents under closed vessel condition. In 1990's synthesis started with solvent-free reactions eliminating the danger of explosion eventually improvising the device designs. Microwave heating not only provides an alternative tool but also improves the yield and reproducibility .Moreover it may lead to novel products by permitting access to the alternative kinetic pathways and stabilizing different energy minima in a reaction vessel. Various aspects of microwave application especially in chemical synthesis have been reported and reviewed since then (Rao et al. 1999,Vanetsev and Tretyakov 2007, Tsuji et al. 2005, Yoshikawa 2010,Bilecka \& Niederberger 2010).

There are many distinct frequency bands which have been allotted for industrial, scientific and medical uses. $24.15 \mathrm{MHz}, 2.45$ and $5.80 \mathrm{GHz}$ are world wide accepted frequencies. Still there are few countries where different frequencies are used. In United Kingdom $896 \mathrm{MHz}$ and $40.6 \mathrm{MHz}$ are popular whereas the Netherlands operate on 3.39 and $6.78 \mathrm{GHz}$. (Metaxas and Meredith 1983) 


\section{Experimental set up}

A lot of work has been done on the synthesis of materials due to enhancement of the speed of chemical reactions, demanding improvement in the experimental technology during microwave heating. In most cases domestic microwave oven operated in multimode configuration is being used to perform the experiment. These microwave ovens have certain limitations. Different modes are developed in the main chamber or cavity of the oven, disturbing the power matching when the sample is placed inside. The use of domestic microwave ovens was impeded by possible heterogeneity of the magnetic field, sometimes inducing insufficient reproducibility, non-uniform heating, mixing and precise determination of the reaction temperature. The size, shape and power are the major constraints which should be improved according to the need to get better and efficient results. The use of mono-mode system enabled microwave beam to be focussed on the sample. Therefore it is advisable that the researcher be familiar with different components of the experimental set up used for microwave heating. The block diagram of microwave processing unit is shown in figure 1a. The main chamber as well as parts of this unit can be modified according to the need of individual researcher. In microwave heating high power source is used therefore one should be careful about the hazardous effect of microwaves. The construction and functioning of different components are described in the following sub-sections.

\subsection{Microwave source: magnetron}

Magnetrons, Klystrons, Gyrotrons and Travelling wave tubes (TWT) are used to generate microwave power. These are able to generate high power of microwaves. Each has its own advantages. Klystron offers precise control in amplitude, frequency and phase, while Gyrotron provides much higher power output and beam focussing. TWTs can provide variable and controlled frequency of microwave energy. Solid state devices are also used wherever low power microwaves are needed. Magnetrons are widely popular in microwave heating due to their easy availability and low cost. The size and configuration of a cylindrical magnetron is much suited for microwave ovens as well as for other applications of microwave heating. Magnetron can generate either continuous or pulsed power up to megawatt and frequency between 1-40 GHz. Its power efficiency is around $85 \%$ and life time is $\sim 5000$ hours. The basic structure of a cylindrical magnetron consists of a number of identical cavity resonators arranged in a cylindrical pattern around a cylindrical cathode (Figure 1b).

Two large pole pieces of permanent magnets are used to produce a strong magnetic field normal to the plane of cavities. The anode is kept at higher potential relative to cathode. The electrons emitted from the central cathode are accelerated towards the anode but the presence of transverse magnetic field exerts a torque which causes the electrons to move in a curved path in the drift space. Due to initial perturbation or interaction of electrons an r.f. field is induced in the cavities which propagate in the azimuthal direction with a certain phase velocity. For a constant value of magnetic field the potential difference between anode and cathode is applied to obtain synchronism between the radial velocity of electrons and phase velocity of $\mathrm{n}^{\text {th }}$ spatial harmonics of r.f. field in azimuthal direction. The condition is achieved in which the electrons continuously interact with r.f. field in retarding phase and give up their energy to the field. Waveguides are used to couple the microwave power from the magnetron to the main chamber of the oven. The conducting walls of the guides / 
resonators confine the electromagnetic fields and couple the power from magnetron to the cavity of the oven. A number of distinct field configuration or modes can exist in wave guides. Inside the wave guide either TE or TM modes can propagate but not TEM. These modes are labelled by two identifying integer subscripts ' $n$ ' and ' $m$ 'i.e. $T E_{n m}$ or $T_{M m}$. The integer $\mathrm{n}$ and $\mathrm{m}$ shows the number of half variation of the respective fields along the two transverse coordinates. Each mode has associated with it a characteristic cut-off frequency $\mathrm{f}_{\mathrm{c}, \mathrm{nm}}$ below which the mode does not propagate or a characteristic cut-off wavelength $\lambda_{c, n m}$ above which the mode does not propagate. The dominant mode in a particular guide is that mode having the lowest cut off frequency or highest cut off wavelength. The field configurations for different modes in a rectangular and a circular waveguide are shown in the figures $1 \mathrm{c} \& 1 \mathrm{~d}$.

\subsection{Circulator}

A circulator is a multi-port junction providing one way sequential transmission of power between its ports (Figure 1e) . Port 1 couples to port 2 but not to any other ports similarly port 2 couples with port 3 only and so on. The direction of circulation of the circulator is shown by an arrow marked on the device. In the simplest form the circulator is fabricated by a three port $Y$ junction of rectangular wave guides that is loaded with ferrite cylinder or discs magnetized in the direction normal to the plane of the junctions. The three port junction is completely matched at all its ports. In microwave heating set up, the power is allowed to transmit from port 1 to port 2 and port 3 is terminated by a dummy load which can absorb the reflected power from mismatched load.

\subsection{Tuner}

Tuner is a passive device used to match power from source to unmatched circuit load. Tuners provide variable equivalent inductive or capacitive load by varying the depth of the sliding screws in the wave guide. A typical construction of the sliding screw tuner is made compatible with the experimental set up (figure 1f). The main characteristic of a tuner is its matching performance, expressed as maximum magnitude of load reflection coefficient that can be perfectly matched irrespective of phase. The limit of maximum magnitude depends upon insertion depth of screws and the power level of generator. As input power increases beyond the maximum limit power dissipation in the tuning stub also increases which leads to overheating of the stub, thus melting and damaging the softer surrounding parts. It is therefore important to know safe limits of the input power for the tuner.

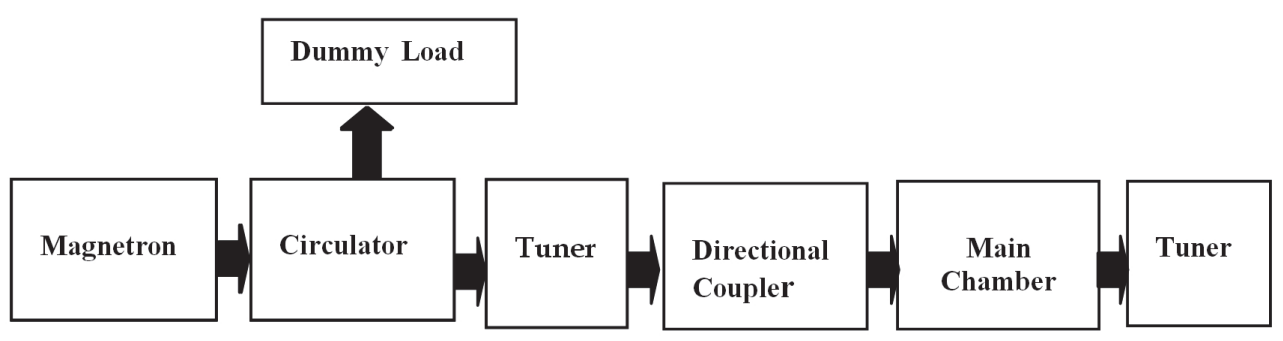

Fig. 1. (a) Block diagram of Microwave Processing Unit 


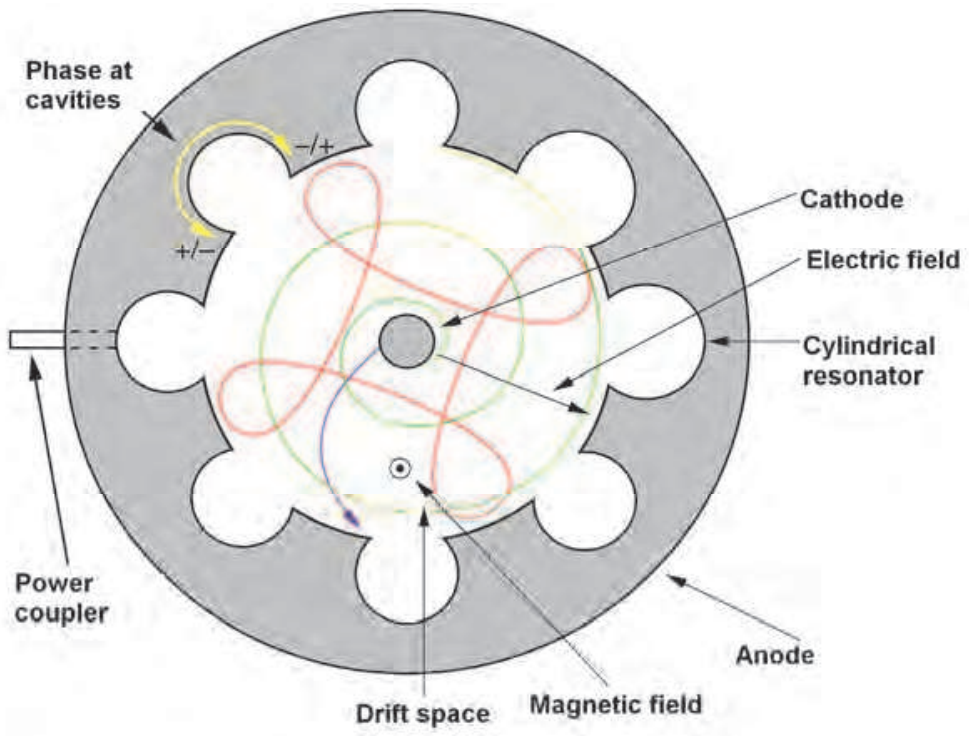

Fig. 1. (b) Construction and working of Magnetron
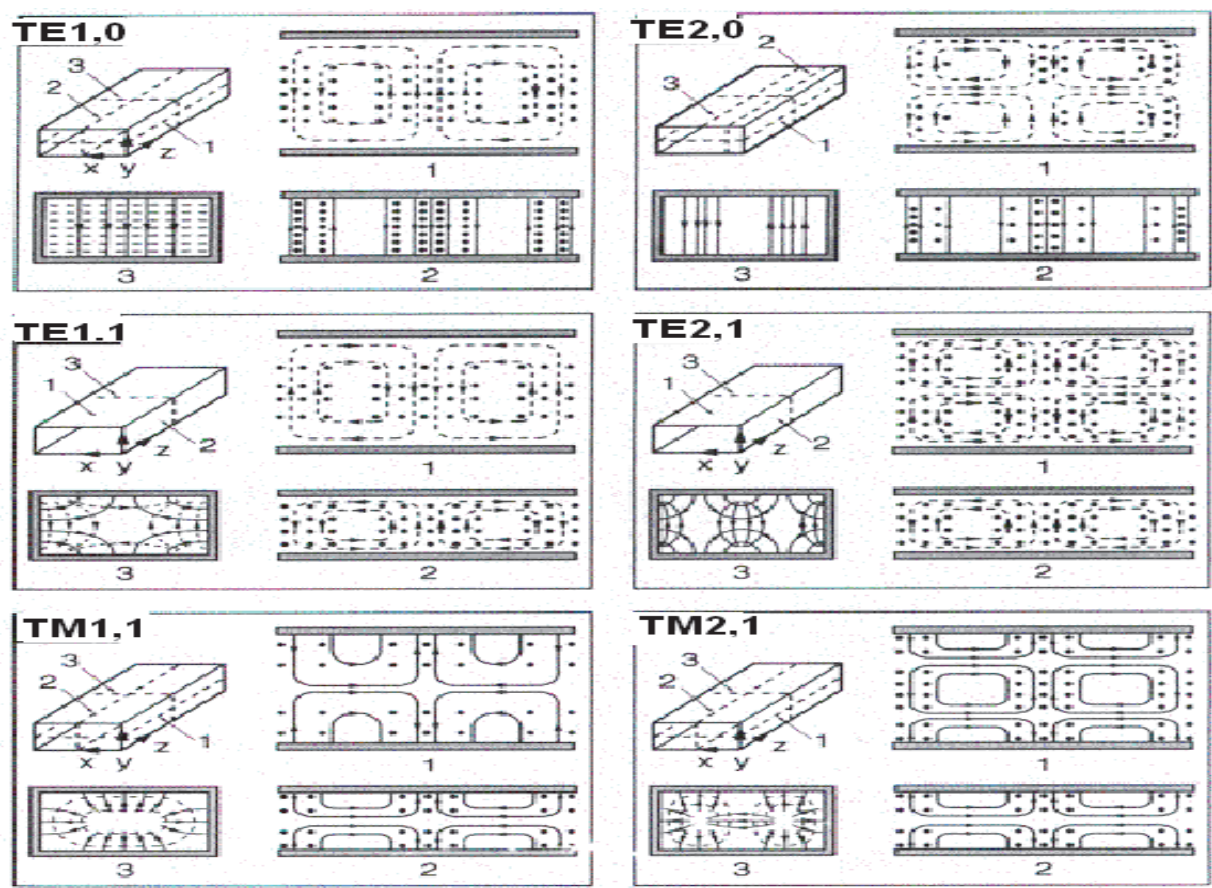

Fig. 1. (c) Field distribution for different modes in a rectangular wave guide 


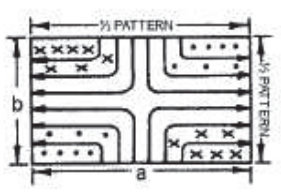

$\mathrm{TE}_{1,1}$

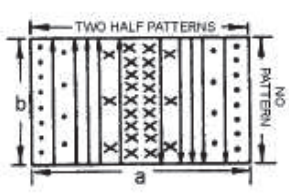

TE 2,0

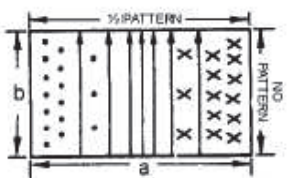

TE 1,0

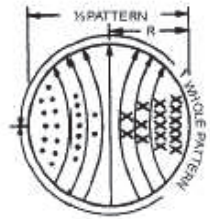

$\mathrm{TM}_{1,1}$

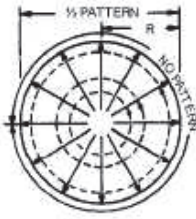

$\mathrm{TM}_{0,1}$

\section{E LINES}

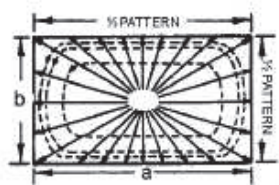

$\mathrm{TM}_{1,1}$

HLINES--- -

Fig. 1. (d) Field distribution for different modes in a Circular wave guide
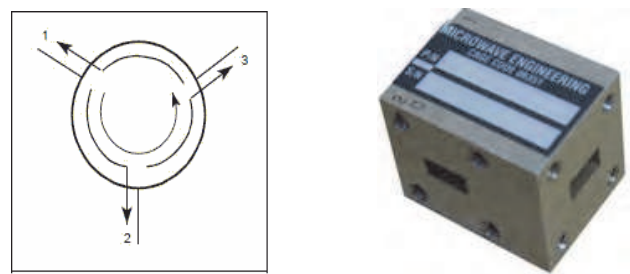

Fig. 1. (e) Schematic diagram of Circulator with its commercial design
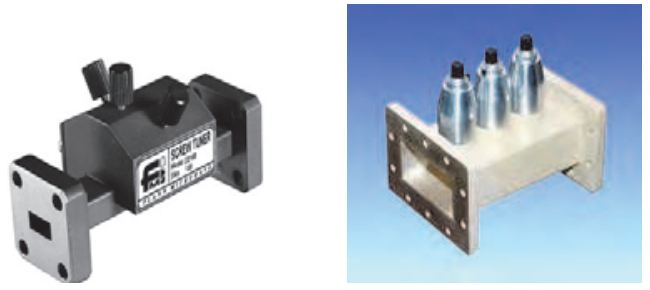

Fig. 1. (f) Types of commercial Tuner
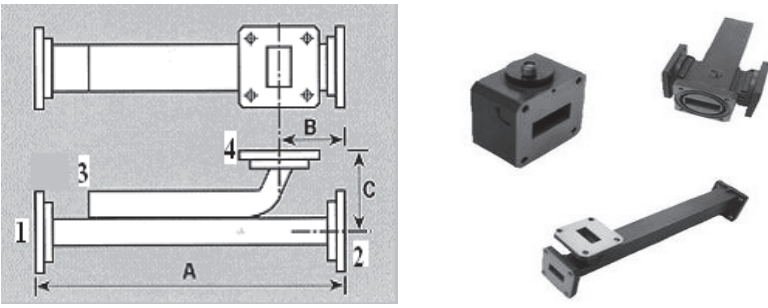

Fig. 1. (g) Schematic diagram of Directional coupler with commercial models 


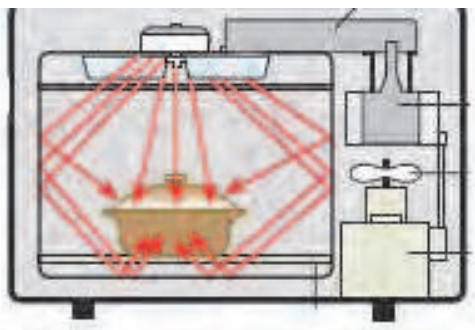

Fig. 1. (h) Main Microwave chamber

\subsection{Directional coupler}

A directional coupler is a four port wave guide junction with the property that power incident in port 1 couples to port 2 with a fraction of incident power coupling to port 4 and no power coupling to port 3. Further power in the back direction entering port 2 couples to port 1 with a fraction of its coupling to port 3 and none of it coupling to port 4 ( figure $1 \mathrm{~g}$ ). The line 1-2 is called primary line and the line 3-4 is called coupled line. All the ports of the directional coupler are well matched. The directional coupler is used to measure incident and reflected power from mismatched load.

\subsection{The Main chamber}

The Main chamber where material to be microwave processed is placed, is like a cavity resonator and microwave power is coupled to it through wave guides (figure 1h). Once the microwave power enters the chamber, standing waves are formed due to multiple reflections from metallic walls. The size of the chamber is of the order of wavelength of microwave used so that multiple modes are excited. In the common domestic ovens the power distribution is uneven inside the chamber resulting into uneven heating of the material. The rotating turn table, therefore, is used inside the oven to make the power distribution equally on the sample. According to the need of microwave-materials interaction, the construction of the main chamber can be modified. In some applications multi chamber ovens are used and energy is coupled through a slot, an array of resonant slots, a radiating horn etc. In some cases modified wave guides are used to excite power in the main chamber. These are called applicators or exciters. Main chamber is loaded with different materials and in different amounts which may change the impedance of the chamber. These applicators are designed always to match the impedance of microwave source and main chamber. Mode stirrer technique is also used to spread the power uniformly in all the directions. The proper cooling arrangements are required to exhaust the unwanted heat from the main chamber. Vollmer (2004) in his special feature demonstrated the intensity distribution within an oven of $29 \times 29 \times 19 \mathrm{~cm}^{3}$ at a height of 8 $\mathrm{cm}$. A horizontal glass plate covered with a thin film of water was placed inside the chamber (without its rotating turn table) on full power for a few seconds. The colour image thus obtained with a thermal infrared camera is shown in figure $2 a$. With only a thin film of water present, the image beautifully illustrates the microwave intensity distribution in a nearly empty chamber. A pronounced horizontal mode structure also shows heterogeneous heating of material. Cheng et al. (2001) studied the distribution of fields in the microwave cavity. The electric (E) field was found maximum in the centre, where the magnetic field is minimum. On the other hand maximum magnetic field is found near the wall with minimum electric field (Figure 2b). 


\section{Microwave heating}

\subsection{Microwave versus conventional heating}

Conventional heating usually involves the use of a furnace or oil bath which heats the walls of the reactors by convection or conduction. The core of the sample takes much longer to achieve the target temperature. On the other hand Microwave penetrates inside the material and heat is generated through direct microwave-material interaction. Moreover volumetric heating, reaction rate acceleration, higher chemical yield, lower energy usage and different reaction selectivity the advantages microwave heating has over conventional methods. Combustion synthesis has been one of the methods used to obtain powder with compositional uniformity. Figure 3 illustrates merit of microwave heating over conventional method during the synthesis of $\mathrm{LaCrO}_{3}$ powder as homogeneous fine particles (Park et al.1998). The mixer solution of the parent constituents was equally divided and kept for combustion separately on a hot plate and in a microwave oven. Combustion products thus obtained were treated in a similar way and morphology was examined by scanning electron microscopy (SEM). The product obtained by hot plate combustion is found to be consisting of hard agglomerates formed by the two dimensional interconnection of spherical particles. On the other hand product of microwave induced combustion appears to be smaller in size and with reduced agglomeration. Kappe and Dallinger (2006) measured temperature of the $5 \mathrm{ml}$ volume of ethanol and observed that throughout the volume temperature rises simultaneously when heated using microwave radiation while sample in oil-heated tube in contact with the vessel wall heats up first ( figure 4). Gedye et al. (1988) carried out different types of organic reactions both in sealed teflon vessels in a microwave oven and under traditional reflux conditions and approximate rate enhancement of between 5 and 1240 times were recorded. Derivatives which normally required 2-3 hours of preparation, effectively synthesized in 2-3 minutes in microwave oven.

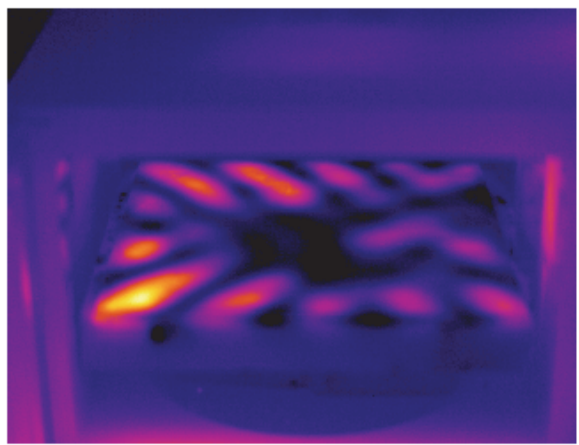

(a)

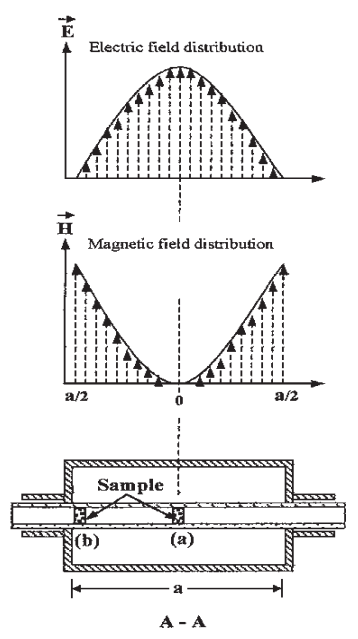

(b)

Fig. 2. (a) Infra red thermal imaging inside microwave oven (Vollmer 2004)

(b) The schematic of the microwave field distribution (E \& M)in the microwave cavity (Cheng et al.2001) 


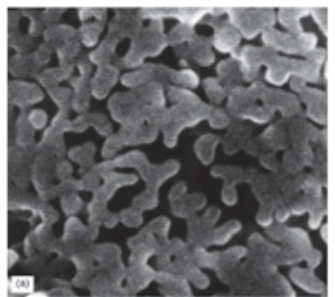

(a)

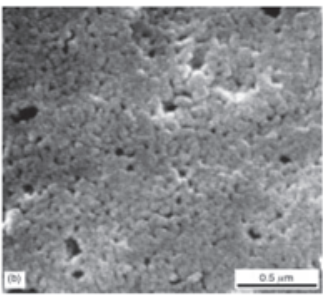

(b)

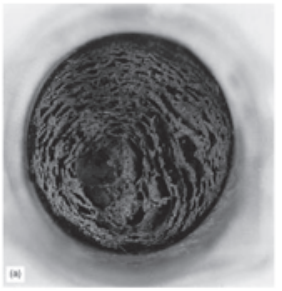

(a)

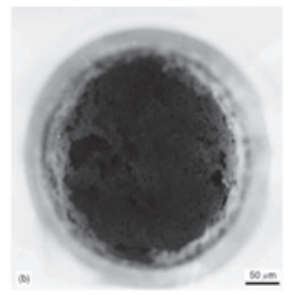

(b)

Fig. 3. Morphology with SEM micrograph of the combustion process (a) hot plate (b) microwave radiation (Park et al. 1998)

A few reactions which were carried out using microwave heating and compared with conventional heating indicating time and energy efficiency of the technique is compiled in Table 1.

\begin{tabular}{|c|c|c|c|}
\hline Compound synthesized & $\begin{array}{l}\text { Reaction time - } \\
\text { microwave }\end{array}$ & $\begin{array}{l}\text { Reaction time - } \\
\text { conventional }\end{array}$ & references \\
\hline $\begin{array}{l}\text { Esterification (benzoic acid } \\
\text { with methanol) }\end{array}$ & $5 \mathrm{~min}$. & $8 \mathrm{~h}$ & Gedye et al (1988) \\
\hline 4-nitrobenzyl ester & $2 \mathrm{~min}$ & $1.5 \mathrm{~h}$ & Gedye et al (1988) \\
\hline $\mathrm{CuBi}_{2} \mathrm{O}_{4}$ & $5 \mathrm{~min}$ & $18 \mathrm{~h}$ & Jones \& Akridge (1995) \\
\hline $\mathrm{Bi}_{2} \mathrm{Pd}$ (Intermetallic) & $4 \mathrm{~min}$. & $12 \mathrm{~h}$ & Lekse et al. (2007) \\
\hline $\mathrm{Ag}_{3} \operatorname{In}$ ( intermetallic) & $2 \mathrm{~min}$. & $48 \mathrm{~h}$ & Lee \& So. (2000), \\
\hline $\begin{array}{l}\text { Layered } \mathrm{Al} \text { and } \mathrm{Zn} \text { double } \\
\text { hydroxide with Na-dodecyl } \\
\text { sulfate }\end{array}$ & $1-2 \mathrm{~h}$ & 2-3 days & Hussein et al. (2000) \\
\hline Bronzes $\left(\mathrm{Na}_{x} \mathrm{WO}_{3}\right)$ & 13-15 min. & - & Guo et al. (2005) \\
\hline Ti N & $30 \mathrm{~min}$ & - & $\begin{array}{l}\text { Vaidhyanathan \& Rao } \\
\text { (1997) }\end{array}$ \\
\hline Cubanite $\mathrm{CuFe}_{2} \mathrm{~S}_{3}$ & $3 \mathrm{~min}$ & 3 days & Chandra et al. 2010 \\
\hline $\mathrm{La}_{2-x} \mathrm{Sr}_{x} \mathrm{Mn}_{2} \mathrm{O}_{4}$ & $30 \mathrm{~s}$ & - & Mingos \& Baghurst. 1991 \\
\hline $\begin{array}{l}\text { High Tc superconductors } \\
\text { YBCO }\end{array}$ & $12 \mathrm{~h}$ & $72 \mathrm{~h}$ & $\begin{array}{c}\text { Binner \& Al-Dawery } \\
\text { (1998) }\end{array}$ \\
\hline Zeolite synthesis & $170^{\circ} \mathrm{C}$ in $30 \mathrm{~s}$ & $1700^{\circ} \mathrm{C}$ in $60 \mathrm{~min}$ & Jansen 2004 \\
\hline $\mathrm{MgB}_{2}$ & $11 \mathrm{~min}$ & - & Dong et al. 2007 \\
\hline $\mathrm{NaAlH}_{4}$ & $2 \mathrm{~h}$ & $8 \mathrm{~h}$ & Krishnan et al. 2009 \\
\hline $\mathrm{La}_{0.2} \mathrm{Sr}_{0.8} \mathrm{Mn}_{0.8} \mathrm{Fe}_{0.2} \mathrm{O}_{3+\Delta}$ & $3 \mathrm{~h}$ & 3 days & Chandra (unpublished) \\
\hline
\end{tabular}

Table 1. Comparison of the reaction times using microwave versus conventional heating. 

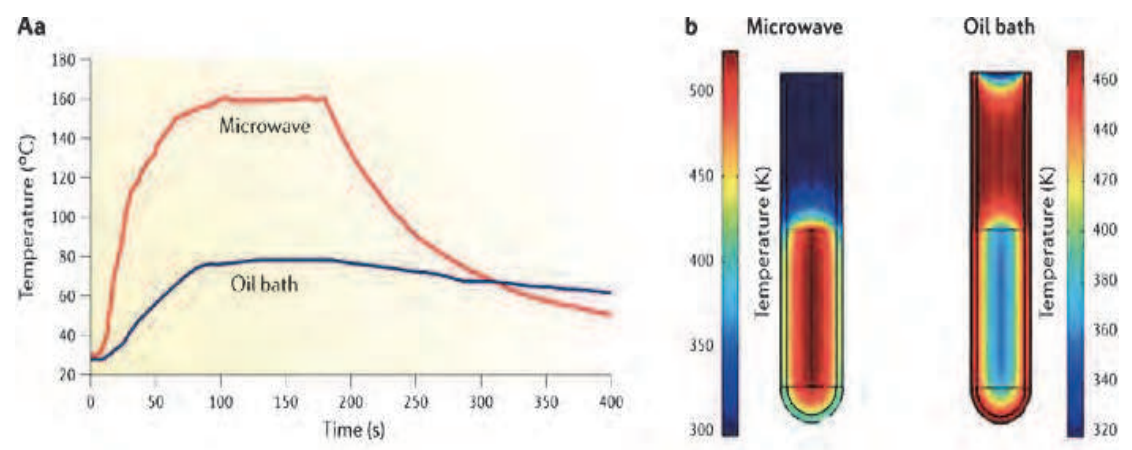

Fig. 4. Temperature profiles for ethanol under microwave radiation and open vessel oil bath condition and temperature gradient $1 \mathrm{~min}$. after heating (Kappe and Dallinger 2006).

\subsection{Interaction of microwaves with materials}

Two factors are important to select the frequency of microwave radiation to heat the materials (i) power absorption in the matter, and (ii) depth of penetration. In electromagnetism, materials are divided into two categories: (i) conductors and (ii) insulators or dielectrics. The distinction between them is not very sharp. The same material may behave as a conductor in one part of electromagnetic frequency and as a dielectric in another. According to Maxwell's theory, the ratio $(\sigma / \omega \varepsilon)$ is considered to be a dividing factor where $\sigma$ is the electrical conductivity; $\omega$ is the angular frequency and $\varepsilon$ is the permittivity/ dielectric constant. For good conductor, this ratio is much greater than unity while in dielectrics, it is much smaller than unity. In dielectrics the electrostatic fields can persist for a long time offering very high resistance when static voltage is applied whereas in good conductors (metals) the static current feels negligible resistance. At higher frequencies, the behaviour depends upon frequency of the electromagnetic waves and corresponding conductivity, permittivity, permeability of the material. The electromagnetic energy propagation through a material medium is associated with the numerical values of permittivity or dielectric constant at that frequency.

The absorption of electromagnetic energy depends upon complex permittivity $\varepsilon$ of that material and can be expressed as

$$
\varepsilon=\varepsilon^{\prime}+\mathrm{j} \varepsilon^{\prime \prime}
$$

where $\varepsilon^{\prime}=$ the real component of permittivity

$\varepsilon^{\prime \prime}=$ the imaginary component of permittivity

The real part or relative permittivity represents the degree to which an electric field may built up inside a material when exposed to the electric field while the imaginary part or dielectric loss is a measure of amount of the field transformed into heat.

The Loss angle $\delta$, the phase difference between the electric field and the polarization of the material is related to the complex dielectric constant as

$$
\tan \delta=\varepsilon^{\prime \prime} / \varepsilon^{\prime}
$$

Thus the $\tan \delta$, the dissipation factor determines the ability of material to transform absorbed energy into heat. 
In terms of microwave interaction, the materials can be classified into three categories:

i. Microwave reflectors e.g. metals

ii. Microwave transmitters - transparent to microwave radiations e.g. fused quartz, ceramics, zircon etc.; $\tan \delta<0.1$

iii. Microwave absorbers taking up energy from the microwave field and heating the materials rapidly; $\tan \delta>0.1$

The electromagnetic energy absorption in dielectric materials primarily is due to the existence of permanent dipole moment of the molecules which tend to orient and reorient under the influence of electric field of microwave. The reorientation loss mechanism originates from the inability of the polarization to follow extremely rapid reversals of the electric field. In the low frequency (up to $100 \mathrm{MHz}$ ) electric field, the dipoles easily follow the changes in the field and their orientation changes in phase with the field. At higher frequencies the inertia of molecules and their interactions with neighbours make changing orientation more difficult and the dipoles lag behind the field. As a result, the conduction current density has a component in phase with the field and therefore power is dissipated in the dielectric material. At very high frequencies (1- $10 \mathrm{THz})$, the molecules can no longer respond to the electric field. At GHz frequency (ideal working range) the phase lag of the dipoles behind the electric field absorbs power from the field and therefore pronounced as dielectric loss due to dipole relaxation.

Another important parameter for microwave heating , penetration depth $\mathrm{D}_{\mathrm{ph}}$ is defined as the depth into the material where the power is reduced to $\sim 1 / 3$ of the original intensity ( Jansen 2004) The absorption coefficient a of dielectric material is related to imaginary parts of dielectric constant $\varepsilon^{\prime \prime}$ or the refractive index. The depth of penetration $\mathrm{D}_{\mathrm{ph}}$ of electromagnetic waves in matter is related to $a$ as $D_{p h}=1 / a$. Thus a material with higher dissipation factor will have lower penetration depth. The wavelength of the radiation also has influence on penetration depth. For microwave prone materials the absorption coefficient at $2.45 \mathrm{GHz}$ is moderate and depth of penetration is of the order of $10 \mathrm{~cm}$ to $1 \mathrm{~m}$ which results in absorption of microwave everywhere in material. The intensity of heat evolution in a sample depends on electrophysical properties of the materials, frequency, intensity of the applied field, penetration depth of the electromagnetic waves into the substance under treatment and geometric size of the sample. The dielectric parameter of the matter and the penetration depth depend strongly on temperature and therefore varies during heating.

Water is an excellent example of polar molecule. The principle of microwave heating of polar molecules (for the case of water) is illustrated very nicely in figure 5 (Tsuji et al. 2005). These molecules absorb microwave energy rapidly and the rate of absorption varies with the dielectric constant of the material. The electric dipoles present in the dielectric materials respond to the applied electric field of microwave. Resistive heating occurs when the dipolar orientation is unable to respond to the applied microwave field resulting into a phase lag.

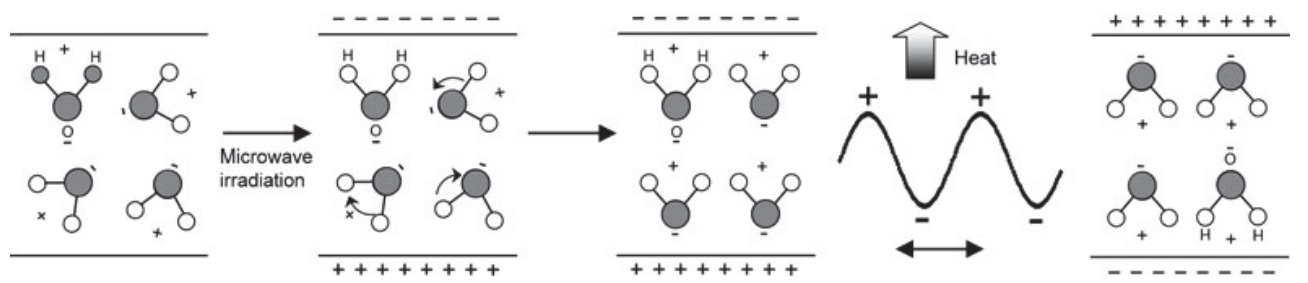

Fig. 5. Heating mechanism of water due to microwave field. (Tsuji et al. 2005) 
In general, the dipolar species in any medium possess a characteristic relaxation time $\tau$ and frequency dependent dielectric constant. If the dipolar relaxation is characterized by a single relaxation time, then dependency with frequency is given by Debye equations (Rao et al. 1999):

$$
\begin{aligned}
& \varepsilon^{\prime}=\varepsilon_{\text {in }}+\left(\varepsilon_{\mathrm{s}}-\varepsilon_{\text {in }}\right) /\left(1+\omega^{2} \tau^{2}\right) \\
& \varepsilon^{\prime \prime}=\left(\varepsilon_{\mathrm{s}}-\varepsilon_{\text {in }}\right) \omega \tau /\left(1+\omega^{2} \tau^{2}\right)
\end{aligned}
$$

Where $\varepsilon_{\mathrm{s}}$ and $\varepsilon_{\text {in }}$ are the zero frequency and the infinite frequency dielectric constants respectively. $\varepsilon^{\prime \prime}$ varies with frequency giving rise to a characteristic frequency at $\omega=1 / \tau$. For water , $\varepsilon^{\prime \prime}$ being significant at $2.45 \mathrm{GHz}$, a rapid dissipation occurs as heating of water.

Microwave interaction with materials can be predicted if dielectric properties ( relative dielectric constant $\varepsilon^{\prime}$ and relative dielectric loss factor $\left.\varepsilon^{\prime \prime}\right)$ are known. The loss tangent $\tan \delta=\varepsilon^{\prime \prime} / \varepsilon^{\prime}$ is an indicator of the ability of the material to convert absorbed energy into heat. A good absorber has $\tan \delta \geq 0.1$ while those with $\tan \delta \leq 0.01$ are transparent to microwave. Materials with high loss factor at the frequency of the incident radiation will heat at a faster rate from core to surface. Fused quartz, zircon, several glasses, ceramics and Teflon are good transmitter while in $\mathrm{SiO}_{2}$, dielectric constant and losses do not show much dispersion hence no heating occurs. Tap water is microwave active as compared to distilled water. Alumina is microwave transparent at room temperature at $2.45 \mathrm{GHz}$ but heats up efficiently at $1000^{\circ} \mathrm{C}$ becoming highly susceptible at $1500{ }^{\circ} \mathrm{C}$. $\mathrm{SiC}$, on the other hand usually heat well at moderate frequency (Kubel 2005). Microwave susceptors are fabricated by depositing very thin layer of aluminium on polyster (PET) sheets. The thin layer of aluminium absorbs part of microwave energy creating currents in the metal. The thickness of the layer limits the currents hence preventing arcing however the currents are high enough to heat the susceptor to a high temperature. Such arrangements are popular in food industry. A list of materials useful during microwave heating process along with $\varepsilon^{\prime}, \varepsilon^{\prime \prime}$, tan $\delta$ and $D_{\text {ph }}$ is tabulated in Table 2.

\subsection{Microwave interaction in metals}

Skin depth and penetration depth are important parameters in microwave heating of metals. When microwaves are incident perpendicularly on the surface of the materials, its intensity decreases progressively due to dissipation inside the volume of the materials. Therefore the term 'penetration depth $D_{p h}$ is defined as the distance in the direction of penetration at which the incident power is reduced to half of its initial value (Rao et al. 1999):

$$
\mathrm{D}_{\mathrm{ph}}=3 \lambda_{0} /\left[\text { [ 8.686п } \tan \delta\left(\varepsilon^{\prime}\right)^{1 / 2}\right]
$$

Where $\lambda_{0}$ is the wavelength of the microwave radiation.

In metals microwave propagation is usually described in terms of 'skin depth'. The skin depth is defined as the depth at which the magnitude of electric field drops to 1/e of the value at the surface and is given as (Newham et al. 1991):

$$
\delta=1 /(\text { vп } \mu \sigma)^{1 / 2}
$$

where $v$ is the microwave frequency $(\omega=2 \pi v), \mu$ is permeability of the free space and $\sigma$ is the electrical conductivity.

The behaviors of bulk metal pieces and metal powder under microwave radiation are different. Skin depth in metal is very low and varies as $(\sigma)^{-1 / 2}$ showing less penetration of 
microwaves. In large metals and metal films, electric field gradients occur in the microwave cavity giving rise to electric discharge. In metal powder, due to eddy currents and plasma effects, very rapid heating takes place without any discharge.

\begin{tabular}{|c|c|c|c|c|c|}
\hline Material & $\varepsilon^{\prime}$ & $\varepsilon^{\prime \prime}$ & $\tan \delta$ & $\mathrm{D}_{\mathrm{ph}}(\mathrm{cm})$ & Reference \\
\hline Silicon Carbide & 10.5 & 11.0 & 1.048 & 0.28 & Clark \& Sutton (1996) \\
\hline Ethylene Glycol & 41 & 41 & 1.350 & - & $\begin{array}{c}\text { Kappe \& Dallinger } \\
\text { (2006) }\end{array}$ \\
\hline Active C & 7 & 2 & 0.286 & - & Vos et al. 2003 \\
\hline Ethanol & 24.3 & 6.08 & 0.250 & - & $\begin{array}{c}\text { Kappe \& Dallinger } \\
\text { (2006) }\end{array}$ \\
\hline Methanol & 32.7 & 20.9 & 0.240 & - & 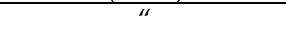 \\
\hline Wood & 1.591 & 0.033 & 0.0207 & 3.57 & Rattanadecho(2006) \\
\hline Wood ( $40 \%$ water) & 5.1 & 1.12 & 0.2196 & 4.0 & Starck et al (2005) \\
\hline Soda Lime Glass & 6.0 & 1.20 & 0.200 & 1.5 & \\
\hline$\underset{\|}{\text { Water ( Distilled } 25^{\circ} \mathrm{C} \text { ) }}$ & 78.3 & 12.3 & 0.157 & 1.5 & Shulman (2002) \\
\hline Water ( Deionized) & 78.2 & 10.3 & & 5.7 & Schiffmann (1986) \\
\hline Water $(0.5 \%$ salt $)$ & 75.8 & 15.6 & & $\begin{array}{l}1.68 \\
1.09\end{array}$ & \\
\hline Ice & 3.2 & 0.0029 & 0.0009 & 1.09 & Starck et al.(2005) \\
\hline Water ( Tap Water) & 67.5 & 6.0075 & 0.089 & & Hasna (2009) \\
\hline $\mathrm{SiC}$ & 10.4 & 0.9 & 0.0865 & 7 & Starck et al (2005) \\
\hline $\mathrm{SiO}_{2}$ & 3.066 & 0.215 & 0.0701 & - & Vos et al. 2003 \\
\hline Soot & $\sim 10$ & $\sim 3$ & 0.03 & - & Vos et al.2003 \\
\hline Lithium Disilicate Glass & 7.5 & 0.17 & 0.023 & 1.30 & Clark \& Folz \\
\hline Silicon Nitride & 0.68 & 0.015 & 0.022 & 8.13 & Starck et al (2005 \\
\hline Zirconia & - & - & 0.015 & 100 & Hasna (2009) \\
\hline PVC & 2.9 & 0.016 & 0.0055 & 200 & Starck et al (2005 \\
\hline $\begin{array}{l}\text { Natural Rubber- } \\
\text { With S (3.0pph) }\end{array}$ & 2.27 & 0.004 & 0.002 & 173400 & Makul et al.(2010) \\
\hline With S (3pph) \& C black & 3.366 & 0.0142 & 4.219 & 274.0 & \\
\hline Boron Nitride & 4.35 & 0.0131 & 0.003 & 0.5 & Starck et al (2005 \\
\hline pyrex & 4.0 & 0.005 & 0.0013 & 1.8 & " \\
\hline Aluminum Nitride & 9.0 & 0.008 & 0.00089 & 1.18 & “ \\
\hline Polyethylene & 2.3 & 0.001 & 0.00040 & 2.57 & “ \\
\hline PTFE & 2.1 & 0.0006 & 0.0002857 & 4.7 & “" \\
\hline Teflon & 2.1 & 0.0003 & 0.00014 & $\begin{array}{l}2.73 \\
9200\end{array}$ & Shulman (2002) \\
\hline $\begin{array}{l}\text { Alumina } \\
\gamma-\mathrm{Al}_{2} \mathrm{O}_{3}\end{array}$ & $\begin{array}{c}8.9 \\
3.006\end{array}$ & $\begin{array}{c}0.009 \\
0.1720\end{array}$ & 0.00010 & 1.46 & $\begin{array}{l}\text { Starck et al (2005) } \\
\text { Vos et al. } 2003\end{array}$ \\
\hline Fused Quartz & 3.8 & 0.0001 & 0.00003 & 1.9 & - \\
\hline $\mathrm{Cr}_{2} \mathrm{O}_{3}$ & 10.3 & $\sim .0025$ & 0.0002427 & & Dube et al. 2007 \\
\hline Graphite & - & - & - & 0.0038 & $\begin{array}{c}\text { Vatensev \& Tretyakov } \\
2007 \\
\end{array}$ \\
\hline Copper & & & & 0.00026 & $\begin{array}{c}\text { Vatensev \& Tretyakov } \\
2007 \\
\end{array}$ \\
\hline Epoxy resin & & & & $\begin{array}{l}7300 \\
4100\end{array}$ & $\begin{array}{c}\text { Vatensev \& Tretyakov } \\
2007 \\
\text { Shulman (2002) }\end{array}$ \\
\hline Porcelain & & & & 56 & Shulman (2002) \\
\hline Quartz & & & & 1600 & \\
\hline
\end{tabular}

Table 2. Various factors of the materials useful for microwave heating 
Metals are prohibited inside microwave oven due to discharges it produces inside damaging the magnetron supply. However microwaves are being used efficiently in melting of metals. Domestic microwave appliances are based on magnetron, cooled by a stream of air from a fan. The microwaves are reflected by the metal walls till all the energy is absorbed and converted into heat. To be used for metal casting, the domestic oven needs slight modifications (David Reid). The rotating glass plate must be removed, the vents admitting air into the chamber must be taped over and the air from the magnetron cooling redirected to the exterior. The insulation of the sample chamber, a critical factor, has two roles: one it contains the microwave energy within the shell so that the temperature rises to the melting point of the metal; second it protects the walls of the oven. Carbon, magnetite, ferrites are good susceptors of microwave radiation. Early experiments with Carbon ( considered a good susceptor of microwaves) for melting of silver were very discouraging. The un-insulated crucible barely attained red hot. Though insulation helped but it was obvious to find a more efficient absorber. $8 \mathrm{~mm}$ of $\mathrm{SiC}$ paste mixed with clay, applied to inside of ceramic crucible also did not show any results even after 10 minutes of heating. Another crucible with clay-ferrite paste capped with carbon lined shell showed some improvement but silver did not melt. On lining the cap with magnetite-clay mixture and after 15 minutes of firing, silver started melting. A double susceptor- a carbon (graphite) loaded primary coat with magnetite was used successfully to melt small amount of cast iron. The caveat of metal melting is oxidation; hence all melting must be performed in an inert atmosphere or under vacuum.

Agrawal et al. (2006) attempted joining of metal/metal systems by inserting metal powder between metal/ ceramic pieces and irradiating with microwaves. The powder was heated preferentially and thus the steel joints were formed. Attempt of Microwave sintering of metal glasses without crystallization and with addition of Sn for sintering have been reported ( Xie et al. ,2009).

\subsection{Role of magnetic field in microwave heating}

So far the microwave interaction with nonmagnetic material is discussed in which electromagnetic energy loss is associated with complex permittivity of the material. The total microwave power dissipation in a material is given by

$$
\mathrm{P}=2 \Pi\left[\varepsilon_{0} \varepsilon^{\prime} \tan \delta \mathrm{E}^{2}+\mu_{0} \mu^{\prime} \tan \varphi \mathrm{H}^{2}\right]
$$

Where $\varepsilon_{0}$ and $\mu_{0}$ are dielectric permittivity and magnetic permeability of free space, $\varepsilon^{\prime}$ and $\mu^{\prime}$ are the real part of the dielectric permittivity and magnetic permeability of the sample, $\tan \delta$ and $\tan \varphi$ are the dielectric and magnetic loss factor values and $\mathrm{E}$ and $\mathrm{H}$ are the electric and magnetic field values inside the sample. Although $\mathrm{E}$ and $\mathrm{H}$ appear in the equation, mostly it is assumed that entire reaction is due to the losses by the electric field vector. Cherradi et al.( 1994) showed substantial contribution of magnetic field towards the heating of alumina ( at high temperature ), semiconductors and metals. Different materials seem to have different heating behaviours in the $\mathrm{E}$ and $\mathrm{H}$ microwave fields (Cheng et al. 2001). The high conductivity samples like metallic powders could be efficiently heated up in the magnetic field while the low conductivity samples (ceramics, alumina) got much higher heating in the pure electric field. For the same material $(\mathrm{Cu})$, the compact sample absorbed lot of microwave energy in the magnetic field while the solid sample did not respond in the same condition. Roy et al.(2002) demonstrated that the common crystalline phase can be made non crystalline and hard magnets can be softened in the solid state by heating them in magnetic component of microwave radiation. The decrement in the resistance for polycrystalline LCMO films observed under influence of microwave radiation was explained by tunnelling of carriers 
through inter-grain boundaries (Lučun et al. 2007). The induced resistance depended on the sample position in the wave guide thereby near the narrow wall of the wave guide, magnetic component of the radiation had significant influence on the magneto-resistive properties of the film. While studying the dependence of electron paramagnetic resonance (EPR) of some manganites on microwave power, it was observed that the sample became unusually hot at high microwave power (Singh 2007) due to the interaction of the spin of $\mathrm{e}_{\mathrm{g}}$ electron of $\mathrm{Mn}^{3+}$ with the magnetic component of microwave field.

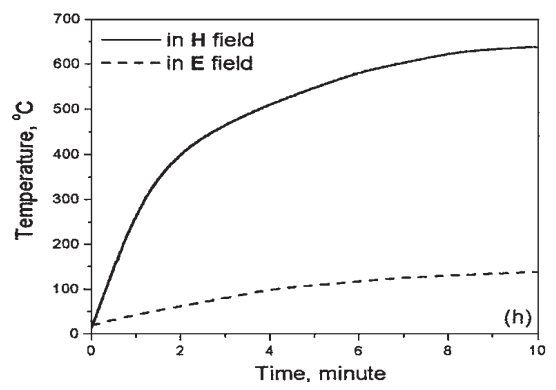

Fig. 6. Comparison of the heating rate of powdered tungsten carbide- cobalt (WC-Co) sample (microwave power 200W) (Cheng et al. 2001)

\section{Examples of microwave synthesis}

The nature of the minerals as they exist at atmospheric pressure represents only a part of their real nature. The pressure and temperature conditions impart strong influence on the structure and characteristics of the mineral. As one travels from Earth's mantle to the core, both temperature and pressure conditions changes drastically. The range of pressure and temperature prevailing at the surface of the Earth can be compared to those on other planets of the solar system. For example Sulfide minerals occur in the Earth's as well as in the Mars's mantle. Determining the thermodynamical properties of sulfides by synthesizing minerals under various laboratory conditions and comparing their behavior with natural one would be very important to understand the paragenesis of their formation in the planetary system. One of the examples described here is orthorhombic cubanite $\mathrm{CuFe}_{2} \mathrm{~S}_{3}$ which occurs in mineral deposits along with chalcopyrite $\left(\mathrm{CuFeS}_{2}\right)$ and pyrrhotite $\left(\mathrm{Fe}_{1-x} \mathrm{~S}\right)$ under certain conditions. Orthorhombic cubanite is very sensitive to temperature and pressure. At $\sim 200^{\circ} \mathrm{C}$ or $\sim 4 \mathrm{GPa}$, the orthorhombic structure transform to cubic isocubanite. The discovery of cubanite in CI chondrites and stardust in comet wild 2 clarified the mechanism of large scale mixing of low-temperature assemblages in early solar system. The phase relationship in $\mathrm{Cu}-\mathrm{Fe}-\mathrm{S}$ determines the co-existing phases as a function of temperature and point to the unique combination of temperature and composition (Yund and Kullerud 1966). Owing to the unique physicochemical conditions needed, orthorhombic cubanite is difficult to synthesize under normal laboratory environment. In this direction, synthesis of this rarely found mineral, cubanite $\left(\mathrm{CuFe}_{2} \mathrm{~S}_{3}\right)$ was successfully attempted using conventional as well as microwave heating. The rapid microwave heating seems to be advantageous over conventional technique showing a characteristic peak of cubanite at $d=3.22 \AA$ (Pareek et al. 2008, Chandra et al. 2010,2011). It is reported that synthesis of orthorhombic cubanite depends not only on the preparatory conditions (controlled heating 
and cooling rate) but also on compositional variation. Figure 7 shows the dependency of synthesis process as well as proportional of sulfur. X-ray diffraction pattern of resistive heated sample slowly heated and cooled to room temperature (a) with stoichiometry $\mathrm{Cu}: F e: S:: 1: 2: 3$ has been analyzed as isocubanite ( cubic cubanite), pyrrhotite and chalcopyrite while rapidly heated microwave synthesized sample (b) with Cu:Fe:S::1:2:1.5 showed orthorhombic cubanite indicated by the arrows in the figure $7 \mathrm{~b}$. It is to be noted in figure $7 \mathrm{~b}$ that the proportion of sulfur is an important component for the formation of orthorhombic cubanite. The sample was prepared with the same conditions but with increased proportion of Sulfur (Cu:Fe:S::1:2:3). The conspicuously absence of prominent pyrrhotite peak at $\sim 55^{0}$ and formation of cubic isocubanite is observed.

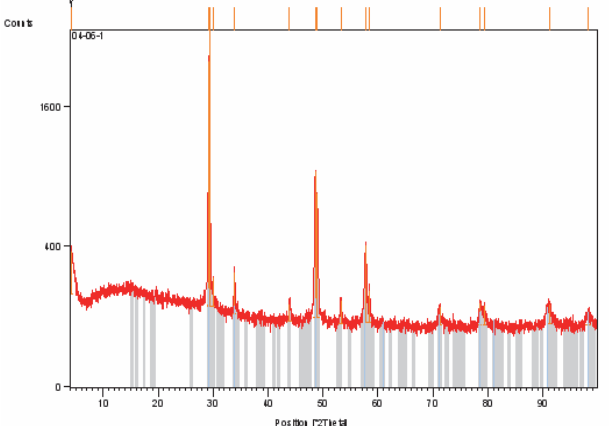

(a)

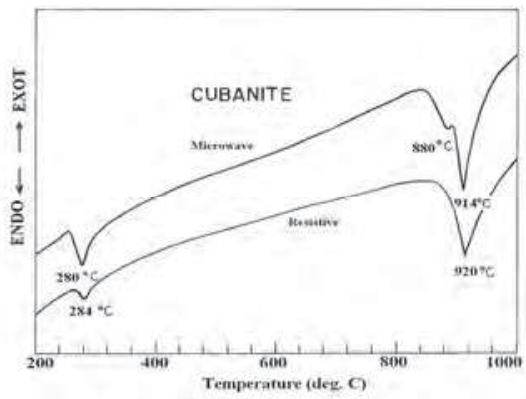

(c)

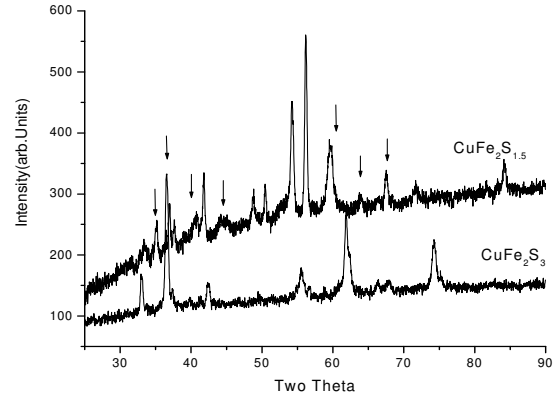

(b)

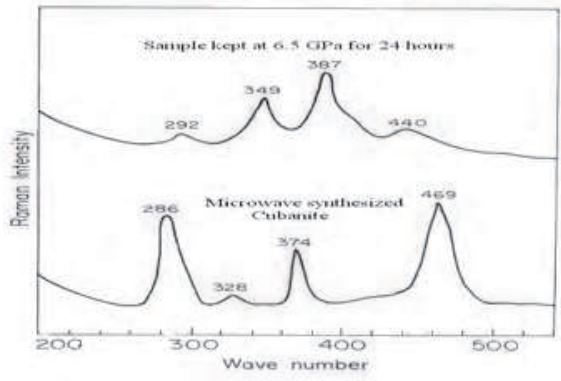

(d)

Fig. 7. X-ray diffraction patterns of (a) resistive heated (b) microwave synthesized cubanite. The arrows mark the orthorhombic cubanite. (c) DTA and (d) Micro-Raman spectroscopic studies of - resistive heated and microwave synthesized cubanite

The intensity at endothermic peak at $280^{\circ} \mathrm{C}$ in the differential thermal analysis (DTA) patterns of synthetic cubanite samples prepared by resistive and microwave heating is a quantitative indicator of the presence of orthorhombic cubanite (Figure 7c). The peak at $880^{\circ} \mathrm{C}$ represents pyrrhotite phase. The absence of an endothermic peak in the region $550^{\circ} \mathrm{C}$ $650^{\circ} \mathrm{C}$ confirms the absence of chalcopyrite in the sample. The Micro-Raman spectroscopic studies on the as prepared synthetic cubanite show strong Raman modes at 286,374 and $469 \mathrm{~cm}^{-1}$ and a weak peak at $328 \mathrm{~cm}^{-1}$ corresponding to the desired cubanite (Fig $7 \mathrm{~d}$ ). The measurements repeated again after pressurizing the sample at $6.5 \mathrm{GPa}$ for $24 \mathrm{~h}$ indicates 
isocubanite. Though x-ray diffraction pattern on conventionally synthesized sample does not indicate orthorhombic cubanite, Mössbauer spectroscopic studies confirm the presence of the phase through its sensitive parameters- magnetic hyperfine interaction and isomer shift. This is first ever study of successfully synthesized cubanite (Chandra et al. 2010).

The microwave dielectric heating effect originates from the natural ability of certain substances to efficiently absorb and to transform the electromagnetic energy into heat. If sufficient heat can be generated at a local level, then chemical reaction may be initiated at a rapid pace. To initialize the process, sometimes, it is necessary to introduce good susceptors of microwave radiation along with the constituents. The reaction can accelerate even if one of the constituents is a good susceptor. Baghurst et al. 1988 carried out pioneering work of the use of microwave dielectric heating for the synthesis of advanced ceramic materialshigh temperature superconducting cuprates and $\mathrm{La}_{2-x} \mathrm{Sr}_{x} \mathrm{CuO}_{4}$. The strong absorbing property of $\mathrm{CuO}$ ( a good susceptor)leads to a rapid and effective pathway for the reaction achieving $700^{\circ} \mathrm{C}$ in $30 \mathrm{sec}$ using domestic oven. However synthesis of ternary CMR perovskites $\left[(\mathrm{La}, \mathrm{Sr}) \mathrm{MnO}_{3}\right]$ are difficult to synthesis because $\mathrm{La}_{2} \mathrm{O}_{3}, \mathrm{MnO}_{2}$ etc attain only 1070 and $321^{\circ} \mathrm{C}$ respectively after $1800 \mathrm{~s}$ ( Gibbons et al. 2000) while $\mathrm{SrCO}_{3}$ does not absorb microwaves to any significant degree (Mingos \& Baghurst 1991).The addition of efficient absorber ( fine grained graphite) in the sample promotes the desired effect by significantly increasing the temperature of the reaction mixture. $\mathrm{Ca}\left(\mathrm{NO}_{3}\right)_{2}$ and $\mathrm{Mn}\left(\mathrm{NO}_{3}\right)_{2}$ are better receptors of microwave as compared to $\mathrm{MnO}_{2}$.In the synthesis of mixed valent perovskites, these nitrates decompose to yield highly oxidising $\mathrm{NO}_{2}$ facilitating the formation of $\mathrm{Mn}^{3+}$ / $\mathrm{Mn}^{4+}$ ( Gibbons et al. 2000). In the synthesis of $\mathrm{MnCo}_{2} \mathrm{O}_{4}$, the aqueous solution of nitrates of $\mathrm{Mn}$ and $\mathrm{Co}$ (non susceptible to microwave radiation) are mixed with carbon powder (good absorber of microwave)which not only acts as a surface enhancing agent but also decreases the decomposition temperature of the nitrates by $100{ }^{\circ} \mathrm{C}$ (Nissinen et al 2003)

Bulk $\mathrm{MgB}_{2}$ with highest $\mathrm{T}_{\mathrm{c}}$ value is not easy to prepare because $\mathrm{Mg}$ is extremely volatile and susceptible to oxidation at elevated temperature. Usually $\mathrm{Mg} \mathrm{B}_{2}$ bulk sample are prepared in a sealed quartz / tantalum tubes or by high pressure sintering. However using Microwave heating, the evaporation and oxidation of $\mathrm{Mg}$ can be significantly reduced. Pellets of the constituent mixture in an alumina boat filled with $\mathrm{SiC}$ powder (used as MW susceptor ) placed in a modified domestic oven operated at $800 \mathrm{~W}$ for 11 min resulted into good crystals of $\mathrm{MgB}_{2}$ (Dong et al 2004)

Bosi et al (1992) predicted the possibility of improved microstructure on superconductors while processing the thin film via microwave heating. If the film thickness is less than the skin depth, "volumetric" heating similar to dielectric might be possible through microwave heating. Also in some thin film applications, where film needs to be deposited on the substrate (such as $\mathrm{Si}$, a potential contaminant of superconductors) microwaves might be useful in the final post-processing stages because selective heating would heat the film keeping the substrate cool, suppressing the diffusion of silicon through the film. Conventional processing of bulk ceramic high $\mathrm{T}_{\mathrm{c}} \mathrm{YBCO}$ superconductors results in low and non-uniform oxygen contents throughout the sintered and annealed bodies, limiting the value of $\mathrm{T}_{\mathrm{c}}$. In contrast microwave heating offers the ability to achieve perfectly uniform and full oxygen content $(x=7)$ and almost full densities (98\%) throughout the bulk ceramic samples. The critical transition temperature was also improved, grain size was uniform and finer than in the conventionally processed sample. In addition the total processing time was approximately a factor of six faster. (Binner \& Al-Dawery 1998)

Mercury sulphide is a useful material and is used widely in many fields such as ultrasonic transducers, image sensors, photoelectric devices, conventional preparation of the item is 
not popular because of the toxicity of mercury. Microwave heating found to be a fast (5-10 $\mathrm{min})$, convenient , energy efficient and environment friendly route to the synthesis of nanocrystalline $\mathrm{Hg} \mathrm{S}$ particles with controllable sizes. The size of the particles is found to be dependent on various solvent used e.g. Absolute ethanol, tetra-hydro-furan, distilled water, dimethyl formamide (DMF), and 20\% DMF solutions respectively (Wang et al 2001)

The unprecedented flexibility of ink-jet printing makes it very suited for rapid prototyping applications. The ink-jet printing requires conducting tracks by using inks based on organic silver or copper precursors. The precursor is reduced to corresponding metal via a postprinting annealing step. Conventional radiation-convection-conduction heating is the most commonly used method wherein sintering temperatures are $\sim 200^{\circ} \mathrm{C}$. Therefore many potentially interesting substrate materials such as polymers cannot be used. The required long sintering time ( $\sim 60 \mathrm{~min}$.) also implied the non feasibility of the method for fast industrial application. Replacement of microwave heating fulfils the requirement for a fast, simple, cost effective and selective heating of only the printed components (Perelaer 2006) In the manufacturing of diamonds, the processing through carbon is either by high temperature / high pressure (HTHP) or by high temperature/ low pressure deposition process such as Chemical Vapour Deposition (CVD). Crystalline diamonds predominantly composed of $\{100\}$ and $\{111\}$ faces was grown on a non-diamond substrate from a gaseous mixture of hydrogen and methane under microwave glow discharge condition (Kamo et al. 1983) Diamond wafers with a thickness ranging to several microns is a promising material

for Infra-red optics as well as for $\mathrm{x}$-ray and particle detector. To be economically viable, the chemical vapour deposition of diamond should be performed at a large area. Compared with hot filament CVD and other techniques, microwave plasma can provide a large and good quality diamonds using hydrocarbon radical and atomic hydrogen (Weidong 2006).

Use of microwave heating in drying of wood is becoming popular. Rattanadecho(2006) studied the influence of irradiation times, working frequencies and sample size dependency of microwave heating patterns within the wood under various conditions. At $2.45 \mathrm{GHz}$, the power distribution as well as temperature distribution within the sample displays a wavy nature due to the thickness of the sample being close to the penetration depth. Most of the heating seems to occur at the centre of the test sample due to maximum electric field distribution.

\section{Hazards of microwaves}

It is well established fact that microwave radiations cause serious health problems like loss of appetite, irritation, discomfort, fatigue and headaches known as microwave syndrome. Dr. Neil Cherry, a pioneer worker in the field of r.f. radiation hazards in a detailed study had proved beyond doubt that r.f. radiation cause sleep disturbance, melatonin reduction and cancer in many parts of the body. Effect of microwave radiation on the human biochemistry and physiology depend upon frequency, intensity and duration of exposure of radiation. The safe limit for microwave radiations as per WHO and ICNIRP guidelines is $\sim 2.5 \mathrm{~mW} / \mathrm{cm}^{2}$ or less. A simple device called microwave leakage meter should be used to check the level of microwave radiations around the microwave heating system and if it is more than the prescribed limit arrangements must be made to shield the system or proper absorbing materials should be put to reduce the level below tolerable limit. Nothing in the life is absolutely safe. Even ultra violet (UV) part of solar radiation is known to pose serious hazards. It is good practice to always wear microwave safe gloves, apron, and goggles now available in the market while working near microwave heating systems. 


\section{Conclusion}

In modern days where scientific finding and technology are going hand in hand, any new synthesis technique which would save time in synthesis of new materials or improving the thermo-dynamical properties of the materials by sintering would be extremely beneficial. In this respect microwave heating is faster, eco-friendly and has potential to contribute towards the synthesis of nano particles. This Green Chemistry approach not only reduces the synthesis time but also suppresses the side reactions thus improving the yield and reproducibility. Familiarity with basic physical concepts and practical aspects of microwave heating process in chemical industry may definitely increase the speed and efficiency of yield.

\section{Acknowledgment}

We acknowledge DST, CSIR- New Delhi and PLANEX (ISRO), Ahmedabad for providing the financial support. We thank Ms Pooja Sharma for the help rendered by her during manuscript typing.

\section{References}

Agrawal, D., Cheng, J., Peelamedu, R., Fang, Y., \& Roy, R. (2006). Materia Japan. Bulletin of Japan Institute of Metals. 45, 574-576.

Baghurst, D. R., Chippindale, A. M., \& Mingos , D. M. P., ( 1988). Microwave synthesis for superconducting ceramics, Nature 332, 311.

Binner, J. G. P. \& Al-Dawery, I. A. H. (1998). Bulk YBCO high $-\mathrm{T}_{\mathrm{c}}$ superconductors with uniform and full oxygen content via microwave process, Superconductor Science and Technology, 11, 449-457.

Bilecka, I., \& Niederberger, M., (2010). Microwave chemistry for inorganic nanomaterial synthesis, Nanoscale 2, 1358-1374.

Bosi, S., Beard, G., Moon, A. \& Belcher, W. (1992). Microwave preparation of the $\mathrm{YBa}_{2} \mathrm{Cu}_{3} \mathrm{O}_{7-\delta}$ superconductor. Journal of Microwave power and Electromagnetic Energy, 27, 2, 75-80.

Chandra, U., Parthasarathy, G. \& Sharma, P. (2010). Synthetic cubanite $\mathrm{CuFe}_{2} \mathrm{~S}_{3}$ :Pressure induced transformation to isocubanite. Canadian Mineralogist 48 : 1137-1147

Chandra, U., Pooja sharma \& Parthasarathy, G., (2011). High-pressure electrical resistivity, Mössbauer, thermal analysis and micro-Raman spectrscopic investigations on microwave synthesized orthorhombic cubanite $\left(\mathrm{CuFe}_{2} \mathrm{~S}_{3}\right)$, Chemical Geology (in Press).

Cheng, J., Rustum Roy \& Dinesh Agrawal, (2001). Experimental proof of major role of magnetic field losses in microwave heating of metal and metallic composites, Journal of Materials Science Letters, 20, 1561-1563.

Cherradi, G., Desgardin, J., Provost \& Raveau, B. (1994). In: Electroceramics IV, Vol.II (edited by Wasner R.,Hoffman S.,Bonnenberg and Hoffman C., RWTN), Aschen , p1219.

Clark, D. E. \& Sutton, W. H., (1996). Microwave processing of materials, Annual Review of Material Science, 26, 299-331.

Dong, C., Guo, J., Fu, G. C., Yang, L.H. \& Chen, H. (2007). Rapid preparation of $\mathrm{MgB}_{2}$ superconductor using hybrid mirowave synthesis, Superconductor Science and Technology, 17, L55-L57.

Dube, D. C., Agrawal, D., Agrawal , S. \& Roy, R, (2007). High temperature dielctric study of $\mathrm{Cr}_{2} \mathrm{O}_{3}$ in microwave region, Applied Physics Letters, 90, 124105-1 to 3

Gedye, R., Smith, F., Westaway, K., Ali, H., Baldisera, L., Laberge, L. \& Rousell, J, (1986). The use of microwave ovens for rapid organic synthesis, Tetrahedron Letters, 27, 279- 282. 
Gedye, R. N., Smith, F.E. \& Westaway, K. C., (1988). The rapid synthesis of organic compounds in microwave ovens, Canadian Journal of Chemistry 66:17-26.

Giguere, R. J., Bray, T.I., Duncan, S.M. \& Majetich, G. (1986). Application of commercial microwave ovens to organic synthesis. Tetrahedron Letters, 27:4945-4948

Gibbons, K. E., Jones M.O., Blundell S.J., Mihut A.LI, Gameson I., Edwards P.P., Miyazaki Y.,Hyatt, N.C. \& Porch A. (2000). Rapid synthesis of colossal magnetoresistance manganites by microwave dielectric heating. Chemical Communications 159-160

Guo, J., Dong,C.,Yang, \& Fu,G.(2005) A green route for microwave synthesis of sodium tungsten bronzes $\mathrm{Na}_{x} \mathrm{WO}_{3}(0<x<1)$. Journal of Solid State Chemistry 178: 58-63

Hasna, A.M. (2009), Composite Dielectric heating and drying :The computational process, Proceedings of the World Congress on Engineering (WCE 2009). Vol I, pp679- 686, ISBN 978-988-17012-5-1.

Hyatt, N. C. \& Porch, A., (2000). Rapid synthesis of colossal magnetoresistance manganites by microwave dielectric heating, Chemical Communications, 159-160.

Hussein, M. Z. B., Zainal, Z. \& Ming, C. Y., (2000). Microwave-assisted synthesis of Zn-Al layered double hydroxide-sodium dodecyl sulphate nano composite, Journal of Materials Science letters, 19, 10, 879-883.

Jansen , K.. (2004). Verified synthesis of zeolite materials, In: (2nd Revised edition), Microwave Technology in Zeolite Synthesis. http://www.ionline.org/synthesis/VS_2ndEd/MicrowaveTech.htm

Jones, S.D., \& Akridge, J. R., (1995)., In: Handbook of solid state batteries and capacitors. Munshi, M.Z.A., Ed. World Scientific , Singapore , 209.

Kamo,M., Sato,Y., Matsumoto, S., \& Setaka, N., (1983), Diamond synthesis from gas phase in microwave plasma, Journal of Crystal Growth, 62(3) , 642-644.

Kappe, C. O., \& Dallinger, D., (2006). The impact of microwave synthesis on drug discovery, Nature Reviews Drug Discovery, 5, 51-63

Krishnan,R., Agrawal, D. \& Dobbins, T., (2009). Microwave irradiation effects on reversible hydrogen desorption in sodium aluminium hydrides $\left(\mathrm{NaAlH}_{4}\right)$, Journal of Alloys and Compound, 470, 250-255.

Kubel ,E., (2005). Advancements in Microwave heating technology, IndustrialHeating.com (January issue) , 43-53.

Lee, C. C., \& So, W.W., (2000). High temperature silver- indium joints manufactured at low Temperature, Thin solid films, 366, 196-201.

Lekse, J. W., Stagger, T.J., \& Aitken, J.A., (2007). Microwave metallurgy: synthesis of intermetallic compounds via microwave irradiation, Chemistry of Materials, 19, 3601-3603

Lučun, A., Butkute, A., Maneikis, O., Kiprijanovic, O. Anisimovas, F., Gradauskas, J., Suziedelis,A., Vengalis ,B., Kancleris,Z.,\& Asmontas ,S., (2007). Magnetoresistance of polycrystalline $\mathrm{La}_{0.7} \mathrm{Ca}_{0.3} \mathrm{MnO}_{3}$ films in a microwave magnetic field, Acta Physica Polonica 111: 147-152

Makul, N. \& Rattanadecho, P., (2010). Microwave Pre-curing of natural rubber compounds using a rectangular wave guide, International Communication in Heat and Mass Transfer, 37, 914-923.

Metaxas, A.C. \& Meredith, R. J., (1983). Industrial Microwave Heating, Peter peregrinus Ltd., London, UK (for IEE).

Mingos D. M. P., \& Baghurst, D. R., (1991). Application of microwave dielelctric heating effects synthetic problems in chemistry, Chemical Society Reviews, 20, 1, 1-47.

Newham, R. E., Jang, S. J., Xu, M. \& Jones, F., (1991). Fundamental interaction mechanisms between microwave and matter, Ceramic transactions, 21, 51.

Nissinen, T., Kiros, Y., Gasik, M. \& Leskela, M., (2003). Microwave synthesis of $\mathrm{MnCo}_{2} \mathrm{O}_{4}$ nanoparticles on carbon, Chemistry of Materials, 15, 4974. 
Pareek, S., Rais, A., Tripathi, A., \& Chandra, U., (2008). Mössbauer study of microwave synthesized $(\mathrm{Cu}, \mathrm{Fe})$ sulfide composite and correlation with natural mineral cubanite, Hyperfine Interaction, 186, 113-120.

Park, H. K., Han, Y. S., Kim, D. K., \& Kim, C. H. (1998). Synthesis of $\mathrm{LaCrO}_{3}$ powders by microwave induced combustion of metal nitrate-urea mixture solution, Journal of Materials Science Letters, 17, 785-787.

Perelaer, J., Berend-Jan de Gans \& Schubert, U. S., (2006). Ink-Jet printing and microwave sintering of conducting silver tracks, Advanced Materials, 18, 2101-2104.

Rattanadecho, P., (2006). The simulation of microwave heating of wood using a rectangular waveguide: influence of frequency and sample size, Chemical Engineering Science, 61, 4798-4811.

Rao, K. J., Vaidhyanathan, B., Ganguli, M. \& Ramakrishnan, P.A., (1999). Synthesis of inorganic solds using microwaves, Chemistry of Materials, 11, 882-895.

Reid David, Melting metals in a domestic microwave. home.c.2i.net/metaphor/mopage.html.

Roy, R., Peelamedu, R., Grimes, C., Cheng, J. \& Agrawal D., (2002). Major phase transformations and magnetic property changes caused by electromagnetic fields at microwave frequencies, Journal of Materials Research, 17, 12, 3008-3011.

Schiffmann, R. F., (1986). Food Product development for microwave processing, Food Technology, 40, 6, 94-98.

Shulman, H. S., (2002). Microwave heating ceramic. www.ceralink.com

Singh R. J., (2007). Heating of manganites by magnetic component of microwave., Indian Journal of Pure and Applied Physics, 45, 454-458.

Starck, A.V., Muhlbauer, A. \& Kramer, C., Hand book of thermoprocessing Technologies : Fundamental processes component safety, (2005). ISBN3-8027-2933-1, Vulken-Verlag GmbH.

Tsuji, M., Hashimoto, M., Nishizawa, Y., Kubokawa, M. \& Tsuji, T., (2005)., Microwave-assisted synthesis of metallic nanostructures in solution, Chemical European Journal, 11, 440-452.

Vaidhyanathan, B. \& Rao, K. J., (1997). Synthesis of Ti,Ga, and V Nitrides: microwave-assisted carbothermal reduction and nitridation, Chemistry of Materials, 9, 1196-1200.

Vanetsev, A. S. \& Tretyakov, Yu.D., (2007). Microwave-assisted synthesis of individual and multicomponent oxides, Russian Chemical Reviews, 76, 5, 397-413.

Vollmar, M. (2004). Physics of microwave oven, Physics Education, 39, 1, 74-81.

Vos, B., Mosman, J., Zhang,Y.,Poels,E., \& Bliek, A. (2003). Impregnated carbon as a susceptor material for low loss oxides in dielectric heating, Journal of Materials Science, 38, 173-182.

Wang, H., Zhang, J. \& Zhu, J. (2001). A microwave assisted heating route method for the rapid synthesis of sphalerite- type mercury sulfide nanocrystals with different sizes, Journal of Crystal Growth, 233, 829-836.

Weidong, M., Chuanxin, W. \& Shenggao, W., (2006). Microwave chemical deposited thick diamond film synthesis using $\mathrm{CH}_{4} / \mathrm{H}_{2} / \mathrm{H}_{2} \mathrm{O}$ gas mixture, Plasma Science and Technology, 8, 3, 329- 334.

Xie, G., Li, S., Louzguin, D.V., Cao, Z., Yoshikawa, N., Sato, M.\& Inoue, A., (2009). Fabrication of $\mathrm{Ni}-\mathrm{Nb}-\mathrm{Sn}$ metallic glassy-alloy powder and its microwave induced sintering behaviour, Journal of Microwave Power and Electromagnetic Energy, 43, 17- 22.

Yoshikawa, N. (2010). Fundamentals and applications of microwave heating of metals, Journal of Microwave Power and Electromagnetic Energy, 44, 1, 4-11.

Yund, R.A. \& Kullerude, G., (1966). Thermal stability of assemblages in Cu-Fe-S system, Journal of Petrology, 7, $454-488$. 


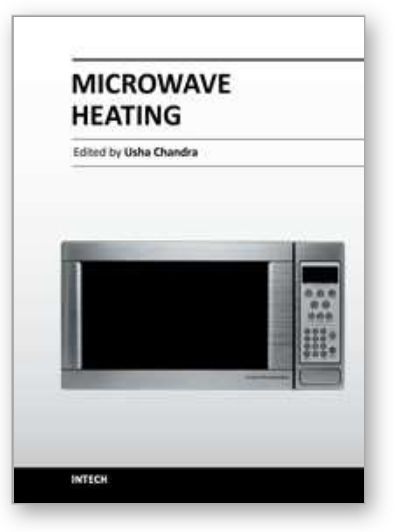

\author{
Microwave Heating \\ Edited by Dr. Usha Chandra
}

ISBN 978-953-307-573-0

Hard cover, 370 pages

Publisher InTech

Published online 27, July, 2011

Published in print edition July, 2011

The Microwave heating has not only revolutionized the food industry but also has extended its wings widely towards its multidimensional applications. Thus it has opened new vistas of potential research in science and technology. The book is compiled into Seventeen Chapters highlighting different aspects varying from epistemological discussion to applicability of conceptual constructs. The inclusion of discussion on the avenues in the field of Chemistry, Health \& Environment, Medical Sciences and Technology makes it an exquisite work for the aspirant Researchers. As the text book for the beginners, it is designed fundamentally to be a reference monograph to the experts providing a passage for future research. The plethora of literatures are available on Microwave Applications but they seldom direct their readers to concentrate on the key aspects behind the success in microwave applications in different fields. Here is the attempt to fill up the gap with this book.

\title{
How to reference
}

In order to correctly reference this scholarly work, feel free to copy and paste the following:

V.K. Saxena and Usha Chandra (2011). Microwave Synthesis: a Physical Concept, Microwave Heating, Dr. Usha Chandra (Ed.), ISBN: 978-953-307-573-0, InTech, Available from:

http://www.intechopen.com/books/microwave-heating/microwave-synthesis-a-physical-concept

\section{INTECH}

open science | open minds

\section{InTech Europe}

University Campus STeP Ri

Slavka Krautzeka 83/A

51000 Rijeka, Croatia

Phone: +385 (51) 770447

Fax: +385 (51) 686166

www.intechopen.com

\section{InTech China}

Unit 405, Office Block, Hotel Equatorial Shanghai

No.65, Yan An Road (West), Shanghai, 200040, China

中国上海市延安西路65号上海国际贵都大饭店办公楼405单元

Phone: +86-21-62489820

Fax: +86-21-62489821 
(C) 2011 The Author(s). Licensee IntechOpen. This chapter is distributed under the terms of the Creative Commons Attribution-NonCommercialShareAlike-3.0 License, which permits use, distribution and reproduction for non-commercial purposes, provided the original is properly cited and derivative works building on this content are distributed under the same license. 